\title{
New Development of Hypoglycemia in a Previously Poorly-Con- trolled Type 2 Diabetic: Ackee Fruit-Induced Hypoglycemia
}

\author{
Summaya Abdul Latif ${ }^{1}$ and Pooja Luthra ${ }^{*}$ \\ ${ }^{1}$ Department of Internal Medicine, Resident, UCONN Health, Farmington, CT, USA \\ ${ }^{2}$ Division of Endocrinology and Metabolism, Department of Medicine, UCONN Health, Farmington, CT, USA
}

*Corresponding author: Pooja Luthra, MD, Division of Endocrinology and Metabolism, UCONN Health, 263 Farmington Avenue, Farmington, CT 06030, USA, Tel: 860-679-3245, Fax:860-679-1217, E-mail: luthra@uchc.edu

\begin{abstract}
Objective: To report a case of hypoglycemia due to Ackee fruit consumption.

Methods: This is a case report and brief review of literature. Results: We report a patient with new onset hypoglycemia due to the consumption of the Ackee fruit. Patient is a 95-year-old Jamaican male with history of uncontrolled, insulin requiring Type 2 diabetes mellitus. He presented with new onset of hypoglycemia and improvement in hemoglobin A1C without any changes in diabetes regimen, other medications or co-morbidities. On investigative questioning, he reported that he had recently received a jar of preserved Ackee fruit, and was consuming small portions of it daily. This coincided with the development of hypoglycemia.

Conclusion: Despite being uncommonly used in the United States, Ackee fruit consumption is a known cause of hypoglycemia. Ackee fruit contains two toxins, hypoglycin A and hypoglycin $B$ that work through the same mechanism to deplete hepatic glycogen stores and cause refractory hypoglycemia. The most severe form of Ackee-fruit toxicity is known as "Jamaican Vomiting Sickness". The disorder is characterized by symptoms of severe hypoglycemia and seizures, ultimately leading to coma and death. Although rare in the United States, it is important to understand and recognize the symptoms of Ackee fruit induced toxicity to avoid late detection and severe complications.
\end{abstract}

\section{Keywords}

Ackee fruit, Hypoglycemia, Jamaican vomiting sickness, Ackee fruit-induced hypoglycemia

\section{Introduction}

The Ackee tree, a native species of West Africa, was introduced into Jamaica in 1776 [1] and has since naturalized in southern California and Florida, as well as the
Antilles, and Central America. Ackee is the national fruit of Jamaica. Consumption of Ackee fruit or 'Blighia sapi$d a^{\prime}$ is uncommon outside these areas. However, Ackee is legally imported in several countries including the USA, Canada, United Kingdom and others. In the USA, the FDA limits the importation to pre-approved companies which have audited and approved Hazard Analysis and Critical Control Points (HACCP) systems in place and that have shown the ability to comply with the stipulated regulatory limit of $100 \mathrm{ppm}$ hypoglycin A in the product. The ripe fleshy Ackee aril is a food staple among poor Jamaican and West African children [2].

Ingestion of unripe Ackee fruit can cause toxicity that is commonly called "Jamaican vomiting sickness" [1]. This usually manifests as an acute gastrointestinal illness but can also be characterized by hypoglycemia and CNS depression [3]. The number of reported cases of Jamaican vomiting sickness has decreased over the years with better education and awareness among the local population about potential dangerous effects of ingestion of the unripe fruit. Jamaicans of all income classes consume Ackee regularly, although persons in the lower income bracket consume Ackee twice as much as those in the middle and upper income brackets [4]. Although most of these cases are reported in parts of West Africa, it is important to know the toxicity associated with this fruit to be able to recognize rare cases in other parts of the world. We report one case where Ackee fruit ingestion caused new onset of hypoglycemia in a previously poorly controlled patient with Type 2 diabetes.

Citation: Latif SA, Luthra P (2017) New Development of Hypoglycemia in a Previously Poorly-Controlled Type 2 Diabetic: Ackee Fruit-Induced Hypoglycemia. Int J Diabetes Clin Res 4:073. doi.org/10.23937/23773634/1410073

Received: September 14, 2017: Accepted: October 24, 2017: Published: October 26, 2017

Copyright: (C) 2017 Latif SA, et al. This is an open-access article distributed under the terms of the Creative Commons Attribution License, which permits unrestricted use, distribution, and reproduction in any medium, provided the original author and source are credited. 


\section{Case Report}

Our patient is a 95-year-old Jamaican male who presented for routine follow-up of his type-2 diabetes mellitus. He has a history of Type 2 diabetes since $1998 \mathrm{com}$ plicated with stable stage 3-4 chronic kidney disease. He was on Glargine 50 units subcutaneously daily at bedtime and Lispro subcutaneously, three times daily with meals, based on estimated carbohydrate intake. In the past, his Hemoglobin A1C (HbA1C) had ranged between 9-10\% (75$86 \mathrm{mmol} / \mathrm{mol}$ ) on this regimen.

During this visit, his $\mathrm{HbA1C}$ was $7.8 \%(62 \mathrm{mmol} / \mathrm{mol})$, which represented a significant improvement from his chronically elevated HbA1C levels. He was self-monitoring his finger stick blood glucose 2-3 times per day. The fasting and random capillary blood glucose in the past month ranged from $50-250 \mathrm{mg} / \mathrm{dl}$ with no clear pattern of hypoglycemia. He had frequent episodes of hypoglycemia 1-2 per day with no clear pattern. He had no recent changes in his diabetes regimen, medications or co-morbidities. His renal function had been stable. He reported no weight loss, dietary caloric reduction or changes in his activity levels and reported compliance with his medications and insulin as prescribed.

On exam, vital signs were within normal limits and the rest of the exam was unremarkable. On further questioning for potential causes of the new onset hypoglycemia, he reported that he had recently received a jar of preserved Ackee fruit from Jamaica and was consuming small portions of it daily. This coincided with the development of hypoglycemia. Given the temporal association of the hypoglycemia with initiation of Ackee fruit ingestion, no further testing was pursued and he was instructed to stop eating the Ackee fruit. He was also educated in detail about existing evidence supporting our recommendation. After discontinuing the Ackee fruit, his blood sugars improved significantly, with no further episodes of hypoglycemia. His blood sugar pattern returned to baseline.

\section{Discussion}

Ackee fruit induced toxicity has been reported since the late $19^{\text {th }}$ century and was the cause of an epidemic in Jamaica in 1954 [5] and has also been associated with an outbreak in Haiti in 2000-2001 [6]. Ackee fruit is known scientifically as Blighia sapida belonging to the Sapindaceae family [3]. It consists of the pod, the seeds, and the fleshy covering or aril. It undergoes various stages of maturity and when mature, the fruit opens up spontaneously to reveal the seeds and the fleshy aril. The fully mature aril is edible but the immature form is highly toxic, while the seeds are known to be poisonous [7]. To prevent toxicity, the seeds and membrane of the Ackee fruit must be carefully removed and the aril thoroughly washed before consumption. Our patient was consuming preserved Ackee fruit that was likely immature given the resultant hypoglycemia that was observed.
The mechanism of Ackee fruit toxicity is well established. The toxins associated with Ackee fruit poisoning were first isolated by Hassel and Reyle in 1954 [8]. They are called hypoglycin because of their ability to induce severe hypoglycemia. Ackee fruit contains two toxins, hypoglycin $A$, found in the arils and seeds and hypoglycin $B$, found only in the seeds of the fruit [9]. Hypoglycin $B$ is a $y$-glutamyl conjugate of hypoglycin $A$ and is a less potent toxin $[1,9]$. The hypoglycin $A$ content in the fruit, both arils and seed decreases with maturity [9]. Hypoglycin B levels in the seeds increase with maturity [9]. The unripe Ackee fruit contains hypoglycin $A$ in a concentration 100 times higher than those in the ripe Ackee fruit [10]. The aril of a self-opened (mature) Ackee fruit has been found to be quite safe for consumption [11]. In 1976, Tanaka, et al. confirmed the ingestion of hypoglycin A from unripe Ackee fruit as the cause of Jamaican vomiting sickness [12].

Upon ingestion, hypoglycin A undergoes $\alpha$-oxidation with the formation of Methylenecyclopropyl-pyruvate (MCP-pyruvate), which is then decarboxylated and conjugated as a Co-A ester (MCPA-CoA). This compound functions to inhibit $\alpha$-oxidation of fatty acids. MCP-pyruvate can be further metabolized to either Methylenecyclopropylacetic Acid (MCPAA) or to Methylenecyclopropylacetyl-Glycine (MCPA-Gly) [13]. MCPAA acts by inhibiting hepatic gluconeogenesis through multiple mechanisms. First, MCPAA reduces several cofactors required for beta-oxidation of long-chain fatty acids, including Coenzyme $A$ and Carnitine, thus halting their metabolization. Inhibition of long-chain fatty acid oxidation leads to decreased NADH and Acetyl-CoA production. Acetyl-CoA is vital for pyruvate carboxylase activation in gluconeogenesis. Additionally, MCPAA inhibits transport of long-chain fatty acids and malate across the mitochondrial membrane. This reduction of fatty acid metabolism then results in increased glucose utilization. With hepatic gluconeogenesis inhibited as well, hypoglycemia soon develops following depletion of hepatic glycogen stores [1]. Ethanol also induces hypoglycemia through inhibition of hepatic gluconeogenesis but in contrast to the mechanism of action of hypoglycin $A$, it results after increase in hepatic NADH leads to decreased conversion of lactate to pyruvate. Ethanol also up-regulates ATF3, a transcriptional repressor that eventually functions to down-regulate gluconeogenic genes [14].

Given the significant toxicity associated with this compound, there have been some efforts to develop a method to test for exposure to hypoglycin A to aid in clinical practice. In 1976, Tanaka, et al. described how MCPAA could be detected in urine treated with barium hydroxide using gas chromatography-mass spectrometry [12]. However recently, Isenberg SL, et al. reported a quantitative method to test for exposure to hypoglycin $A$ and Methylenecyclopropylacetylglycine which can detect metabolites over a range of 0.100 to $20.0 \mu \mathrm{g} /$ 
$\mathrm{mL}$ in the urine [13]. The quantification of hypoglycin $A$ in the blood has also been developed in recent years, using ultra-high performance liquid chromatography-high resolution tandem mass spectrometry. This method has a detection limit of $0.35 \mu \mathrm{g} / \mathrm{L}$ as reported by Carlier, et al. [15]. Similar symptoms can be seen with Multiple Acyl-CoA Dehydrogenase Deficiency (MADD). Sander, et al. developed a method to test for hypoglycin A along with its metabolites in addition to acyl glycines and acyl carnitines that can be observed in acquired MADD [16].

The most severe form of Ackee fruit toxicity is known as Jamaican Vomiting Sickness. The toxicity is dose dependent. It is characterized by severe episodes of vomiting, followed by a quiescent phase and then recurrence of vomiting [1]. It usually manifests within 6-48 hours of ingestion, with recovery usually within 1 week. In severe cases, it can cause seizures, coma and death, usually within 48 hours of ingestion. There can be associated hypoglycemia, and aciduria $[1,3,9,17]$. It may also be associated with toxic liver injury with histology mimicking Acetaminophen overdose $[1,18,19]$. The hepatotoxicity is related to the metabolites of the toxin, while CNS manifestations are attributable to direct toxic effect and hypoglycemia. We were fortunate that our patient's regular consumption of the fruit was in lower doses and his only manifestation was mild hypoglycemia.

The treatment of this disorder is largely supportive, including fluid and electrolyte correction and maintenance of normal blood glucose levels and $\mathrm{pH}$. It is important to monitor blood glucose closely if there is any change in mental status and treat hypoglycemia with intravenous dextrose infusion as early therapy has proven to be extremely effective [20]. The liver enzymes and creatinine should also be monitored serially.

Experimental studies suggest that Glycine and Methylene blue are potential treatments for Ackee fruit poisoning, but there is no clinical data to support the efficacy of these agents, especially when they are administered more than several hours after ingestion. Glycine acts by inhibition of gluconeogenesis from pyruvate by several different mechanisms [21]. Methylene blue increases hepatic gluconeogenesis by directly increasing fatty acid oxidation. Barennes, et al. discovered that therapy with glucose was more effective and there was no added benefit in survival using Methylene blue alone or in combination with glucose [20]. An in vitro study of rat hepatocytes did not support the use of Carnitine as an antidote for the inhibition of multiple Acyl-CoA dehydrogenase enzymes following the consumption of unripe Ackee fruit [22].

Given our patient's age and multiple co-morbidities, he was at high risk of complications with continued ingestion. However, once this was recognized, he was advised to avoid Ackee fruit ingestion and with compliance, his blood sugars normalized with no further episodes of hypoglycemia. He did not require hospitalization or treatment with intravenous dextrose.

\section{Conclusion}

Although rare in the United States, it is important to understand and recognize the potentially severe consequences of Ackee fruit induced toxicity to prevent morbidity and mortality due to late recognition.

\section{Acknowledgement}

This manuscript was initially presented as a poster at the Endocrine Society's $98^{\text {th }}$ Annual Meeting and Expo, April 1-4, 2016 in Boston FRI-727: New Development of Hypoglycemia in a Previously Poorly-Controlled Type 2 Diabetic: Ackee Fruit-Induced Toxicity; Hollis Viray, Adarsh Jha MD and Pooja Luthra MD.

\section{References}

1. Barceloux DG (2009) Akee fruit and jamaican vomiting sickness (blighia sapida koenig). Dis Mon 55: 318-326.

2. McTague JA, Forney R Jr (1994) Jamaican vomiting sickness in toledo, ohio. Ann Emerg Med 23: 1116-1118.

3. Katibi OS, Olaosebikan R, Abdulkadir MB, Ogunkunle TO, Ibraheem RM, et al. (2015) Ackee fruit poisoning in eight siblings: Implications for public health awareness. Am J Trop Med Hyg 93: 1122-1123.

4. Orane A Blake, José C Jackson, Maria A Jackson, CL André Gordon (2004) Assessment of dietary exposure to the natural toxin hypoglycin in ackee (Blighia sapida) by Jamaican consumers. Food Research International 37: 833-838.

5. Feng PC (1969) Hypoglycin-from ackee: A review. West Indian Med J 18: 238-243.

6. Joskow R, Belson M, Vesper H, Backer L, Rubin C (2006) Ackee fruit poisoning: An outbreak investigation in haiti 2000-2001, and review of the literature. Clin Toxicol (Phila) 44: 267-273.

7. Meda HA, Diallo B, Buchet JP, Lison D, Barennes $H$, et al. (1999) Epidemic of fatal encephalopathy in preschool children in burkina faso and consumption of unripe ackee (Blighia sapida) fruit. Lancet 353: 536-540.

8. Hassall CH, Reyle K (1955) Hypoglycin A and B, two biologically active polypeptides from Blighia sapida. Biochem J 60: 334-339.

9. Bowen-Forbes CS, Minott DA (2011) Tracking hypoglycins $A$ and $B$ over different maturity stages: Implications for detoxification of ackee (Blighia sapida K.D. koenig) fruits. J Agric Food Chem 59: 3869-3875.

10. Golden KD, Williams OJ, Bailey-Shaw Y (2002) High-performance liquid chromatographic analysis of amino acids in ackee fruit with emphasis on the toxic amino acid hypoglycin A. J Chromatogr Sci 40: 441-446.

11. Chase GW Jr, Landen WO Jr, Soliman AG (1990) Hypoglycin A content in the aril, seeds, and husks of ackee fruit at various stages of ripeness. J Assoc Off Anal Chem 73: 318-319.

12. Tanaka K, Kean EA, Johnson B (1976) Jamaican vomiting sickness. Biochemical investigation of two cases. N Engl J Med 295: 461-467.

13. Isenberg SL, Carter MD, Graham LA, Mathews TP, Johnson D, et al. (2015) Quantification of Metabolites for Assessing Human Exposure to Soapberry Toxins Hypoglycin A and Methylenecyclopropylglycine. Chem Res Toxicol 28: 1753-1759. 
14. Tsai WW, Matsumura S, Liu W, Phillips NG, Sonntag T, et al. (2015) ATF3 mediates inhibitory effects of ethanol on hepatic gluconeogenesis. Proc Natl Acad Sci U S A 112: 2699-2704.

15. Jérémy Carlier, Jérôme Guitton, Cécile Moreau, Baptiste Boyer, Fabien Bévalot, et al. (2015) A validated method for quantifying hypoglycin A in whole blood by UHPLC-HRMS/ MS. Journal of Chromatography B 978-979: 70-77.

16. Johannes Sander, Michael Terhardt, Stefanie Sander, Nils Janzen (2016) Quantification of hypoglycin A as butyl ester. J Chromatogr B Analyt Technol Biomed Life Sci 1029-1030: 169-173.

17. Gaillard Y, Carlier J, Berscht M, Mazoyer C, Bevalot F, et al. (2011) Fatal intoxication due to ackee (Blighia sapida) in suriname and french guyana. GC-MS detection and quantification of hypoglycin-A. Forensic Sci Int 206: e103-e107.

18. Grunes DE, Scordi-Bello I, Suh M, Florman S, Yao J, et al. (2012) Fulminant hepatic failure attributed to ackee fruit ingestion in a patient with sickle cell trait. Case Rep Transplant 2012: 739238.

19. Hautekeete ML, Degott C, Benhamou JP (1990) Microvesicular steatosis of the liver. Acta Clin Belg 45: 311-326.

20. Barennes H, Valea I, Boudat AM, Idle JR, Nagot N (2004) Early glucose and methylene blue are effective against unripe ackee apple (Blighia sapida) poisoning in mice. Food Chem Toxicol 42: 809-815.

21. Al-Bassam SS, Sherratt HS (1981) The antagonism of the toxicity of hypoglycin by glycine. Biochem Pharmacol 30: 2817-2824.

22. Lieu YK, Hsu BY, Price WA, Corkey BE, Stanley CA (1997) Carnitine effects on coenzyme A profiles in rat liver with hypoglycin inhibition of multiple dehydrogenases. Am J Physiol 272: E359-E366. 